\title{
VIRTUALIZATION OF THE EDUCATIONAL SPACE AND EDUCATIONAL PROCESS IN THE INFORMATION SOCIETY
}

\author{
Alexey Radugin ${ }^{1}$, Olga Radugina ${ }^{2}$, Ksenia Nazarenko ${ }^{3}$ \\ ${ }^{1}$ Doctor of Philosophy, Professor of the Department of Philosophy, Sociology and History, \\ Voronezh State Technical University, 20 years of October street, 84, Voronezh, Russia, \\ E-mail: aradugin@yandex.ru \\ ${ }^{2}$ Doctor of Philosophy, Professor of the Department of Philosophy, Sociology and History, Voronezh \\ State Technical University, 20 years of October street, 84, Russia, \\ E-mail: radugina@yandex.ru \\ ${ }^{3}$ Candidate of Philosophical Sciences, Associate Professor of the Department of Philosophy, \\ Sociology and History, Voronezh State Technical University, 20 years of October Street, 84, \\ Voronezh, Russia, E-mail: petrenkoksenia@vgasu.vrn.ru
}

\begin{abstract}
In the context of the formation of a digital society, the economic and socio-cultural situation dictates the need to use information and communication technologies in the educational process, on the basis of which the process of virtualization of the educational space develops. The purpose of the study is to analyze the virtualization of the educational space, reveal the inconsistency of this phenomenon and show how this process transforms the educational system. In the course of the research, the authors show that the actions of the educational system in this direction are quite strictly regulated by modern market relations. However, the process of virtualization of the educational space should not unfold spontaneously. It should develop progressively and expediently, taking into account the requirements and capabilities of both educational organizations and society as a whole. We should also pay attention to the fact that virtual education should not be allowed to prevail over traditional, live pedagogical interaction, which is more important for the formation of personal qualities.
\end{abstract}

Keywords: virtualization, hyperreality, educational space, inconsistency of virtualization, information society.

\section{INTRODUCTION}

The formation and development of a new social system-the information society-is characterized by large-scale transformational processes that fundamentally change the significance and content of the educational sphere as a key resource for social development. It is impossible to provide a comprehensive justification for these processes without analyzing the essence of virtualization. According to the Russian philosopher D. V. Ivanov, understanding the phenomenon of virtualization is the key to understanding modern reality. The relevance of the study of virtualization of the educational space is determined by the very trend towards virtualization, which manifests itself in virtually unlimited access to information and problematizes the algorithm of its selection in 
the global world. Today, this is becoming a leading vector, both for a specific subject of educational interaction, and for the entire educational space of society and the world, as well as the inconsistency of the system of educational interactions, which acquire a virtual character. The main contradictions of educational interactions are: the contradiction between information that includes non-constructive information flows and the need to obtain constructive knowledge; the deformation of the traditional axiological scale and the formation of new values and meanings, which does not contribute to solving problems related to the selection and systematization of information in the educational process. The virtual axiological scale fundamentally affects the subject of knowledge, calling into question the basic values. Virtualization of the modern educational process defines the goals and objectives of the educational system in a new way. The key to the success of a University graduate is the speed of orientation in the information space, his awareness, and not stable professional knowledge. Specialists who study the problem of virtualization of the educational space testify to the ambiguity of virtualization processes. On the one hand, virtualization contributes to a more thorough ontological content of a specific person, who, with the help of information technologies, is able to form their own individual "information field". On the other hand, virtual trends in education threaten to lose the very essence of such fundamental qualities for the formation of personality as "subjectivity", "intelligence", etc.

\section{METHODOLOGY}

The methodological basis of the research is the categorical apparatus of dialectics applied to the philosophy of education. Dialectical possibilities are present in the correlation of such categories as General - particular, system - element, cause - effect, which allow us to describe the relationship of the real and virtual, subjective and objective, subjective and subjective. The structure of the research is determined by the system and structural-functional methods. The system method allows to give an objective analysis of internal and external relations of subjects of educational interaction, manifesting itself as the General level of education Informatization, and the virtualization layer as part of this process. The structural and functional method allows us to understand the degree of efficiency of the educational process in the conditions of virtualization of the educational space.

\section{DISCUSSION}

The study of this topic has a multidimensional character. Therefore, it is necessary to rely on the work of scientists from various fields of knowledge. First of all, it is necessary to rely on the work of scientists who seek to reveal the essence of information and intensify information processes in their work. These are $z$ 's works. Bauman, D., J. Baudrillard, W. Dysard, M. Castels, K. K. Colin, K. Rogers, O. Toffler, A. D. Ursula, F. Webster, G. fryberg, F. Fukuyama, F. A. von Hayek, R. Harris. In their works, these scientists explore the entire complex of social problems and transformations that are the result of Informatization. Of considerable interest are the works of scientists who address the problems of virtual States in the activities of subjects of the educational process, as well as study the features of the existence of subjects in virtual reality. These include works by $O$. I. Genisaretsky, N. A. Nosov, M. A. Pronin, E. E. Taratuta, and others. An important role is played by the works of authors who study the problems of Informatization of education and the educational process, as well as reveal the main aspects of transformations of the global educational space: E. V. Bryzgalina, V. G. Gorokhova, S. V. Ivanova, V. V. Mironov, V. S. Stepin, E. V. Tkachenko, V. I. Tishchenko, E. V. Ushakova, S. I. Chernykh, N. M. Churinov, and others. The works of I. G. Borisenko, O. V. Kochetkova, A. B. Kochetkova, and I. A. Kochetkova are of particular significance for our research. They analyze the virtual educational space of the University as an effective form of organizing the pedagogical process.

\section{RESULTS}

The transformation of virtuality into everyday life, into a natural component of human life, became possible due to the action of technogenic, socio-cultural, and economic factors. The state of modern society is radically different from the previous historical stages of its development by the rapid changes taking place, the unprecedented growth of new knowledge. According to V. Ovechkin, the existence of man and society as a whole presuppose a gradual strengthening of activities to transform natural resources into an intermediate or final result that meets the diverse needs of people. As the researcher notes, "in the twentieth century, especially in the second half of it, it became obvious that there was a very significant qualitative change - the means and methods of transformation in combination with consumer goods and methods of their application turned from an instrumental Arsenal into an environment of life, which is often designated as man-made". This new environment displaces the natural environment, changing not only the nature of human activities to meet their needs, but also the way of life itself, the system of values and relationships in the human community. Based on the connection of the computer with telecommunications networks, the information revolution that we are witnessing has enabled the emergence of a new social space, thus becoming the starting point for 
Proceedings of SOCIOINT 2020- 7th International Conference on Education and Education of Social Sciences,

fundamental transformations in society. In modern scientific literature, modern society is characterized as an "information society". The interpretation of modern society as informational was introduced into scientific circulation in the late 60s - early 70s of the XX century by Japanese sociologists Yu. Masuda. By definition, E. Masuda, the information society is a post-industrial society at the highest stage of its development, which is based on such an intangible substance as "information ". A new turn in the understanding of modern society is made by the author of the theory of "digital civilization", a canadian scientist D. Tapscott. He emphasizes that modern society can be defined as a knowledge society dominated by the digital way of presenting and processing information. According to him, a special kind of cybersphere is being formed in this society, within which various virtual objects and virtual worlds are being generated and are beginning to play an increasing role in human life. In the information society, there is an intensive process of Informatization of education, and Informatization of education should not be considered as an end in itself .It is a specific tool that can not directly affect the quality of the educational process. This implies its adequate use, which should be correlated with the goals of education. Violation of this principle, according to the fair observation of S. I. However, it leads to the opposite results, because "if the goals are not defined or perceived incorrectly, if the norms and values of education are distorted, no information and communication technologies can improve the quality of education". Informatization of the educational process is closely related to virtualization. The foundations of the relationship between Informatization and virtualization are modern information technologies, in which virtual education practices are implemented in close interaction of various aspects. The above-mentioned processes result in new social challenges, including those arising from the daily penetration of virtuality into everyday life, which must be taken into account in the education system. The virtualization of social experience, followed by the increasingly explicit virtualization of the educational space, is becoming one of the key and iconic phenomena of our time, without the study of which it is impossible to predict the prospects for further development of our world. According to N. Kirillova, "we live in a world of media-an expanding system of mass communications, an "information explosion" ". In such an environment, a person builds their behavior on the basis of extensive information.

Prior to analyzing the situation in the modern education system, characterized by high rates of virtualization, it is necessary to outline the semantic facets of this concept. Researchers of virtual reality differentiate the ontological and psychological aspects of it. According to N. A. Nosov, the ontology of virtual reality is a reality that has the following properties: 1) the relevance of existence; 2) the temporal, spatial autonomy of existence; 3 ) the coexistence of different levels of reality. Bodriar, expanding the ontological boundaries of virtual reality, considers it as a symbolic reality, hyperreality, in which the surrounding reality is transformed into a kind of "audio-visual discourse", which assumes the loss of its spatial and temporal characteristics. D. V. Ivanov also highlighted the fundamental characteristics of virtual reality. in his opinion, this is the immateriality of the impact (the image produces effects that are characteristic of the real); the conditionality of qualities and characteristics (objects are artificial and changeable); ephemerality (freedom of entry/it provides the ability to interrupt and resume existence).

In everyday consciousness, the concept of virtuality is directly associated exclusively with the sphere of artificially created reality based on computer information technologies. However, virtuality does not always occur where telecommunications technologies have a place. An interesting point of view in this regard is expressed by V. Rudnev: "every reality is virtual", since our reality "merges with the virtual realities of human consciousnesses and discourses invented by these consciousnesses (from ideology to religion, understood as a language game)". From the point of view of A.V. Khutorsky, the process of education positioned as social interaction, respectively, should be perceived as a virtual process, since if one or more objects act as subjects of activity interaction - as students and teachers, then this interaction becomes the basis, the beginning of their virtual state, which differs from the state of the same subjects before this interaction. It should be noted that education is both a process and a result of joint activity of subjects and objects of education, associated with the formation of their virtual educational space, the originality of which is determined by these objects and subjects [lbid]. Accordingly, not only remote telecommunications training, but also training as such can be called virtual. The virtual nature of the educational process, its essential connection with information (reproduction, translation, acquisition of new knowledge), as well as new goals and tasks facing education in modern society, determine the penetration of telecommunications technologies into the educational space.

Based on the above, we can assume that the very nature of the virtual has different bases and, accordingly, has a different character - virtuality mediated by a person, and virtuality mediated by a machine. In the first case, virtuality occurs in the process of direct interaction of subjects of the educational process. Learning as such involves modeling real-life situations, immersion in them, and their resolution by students. The originality and, above all, the intellectual, spiritual and ethical benefits of such training are determined precisely by the immediacy of the impact, which cannot be "turned off", "reformatted", or rewound. The property of the spiritual 
Proceedings of SOCIOINT 2020-7th International Conference on Education and Education of Social Sciences, 15-17 June 2020

world of a person becomes only what he really "got over".

Virtuality, mediated by a person, on an unconscious level, still retains a sense of responsibility for their actions, an understanding of the impossibility of correcting what they have done. This fact implies a completely different quality of perception of educational situations, as well as actions to resolve them. It is the human mediation of virtual learning that brings to it a specific component that distinguishes us from other higher mammals spirituality, a focus on the development of the spiritual world of the individual. Accordingly, this kind of training should always precede and prevail over training, the virtuality of which is mediated by technology. Otherwise, there is a risk of irreversible loss of humanity in the person.

Thanks to multimedia, information and telecommunications technologies, people have been able to form a new reality that only simulates the laws of the real world, where everything can be as required by the subject operating this reality. Responsibility, analysis of one's own actions here recede into the background, opening up space for free experimentation, which has no basis, no meaningful meaning, except for pleasure, self-expression, and getting information. However, even here a person does not become free, because the very meaning of freedom, apparently, is hidden in the presence of its antithesis in the fabric of being responsibility. When a person acts in full confidence of the possibility to correct, eliminate mistakes without much effort, we come to a dangerous fact not only for him, but also for the whole society-the atrophy of social responsibility. In many ways, the attitude to the everyday world itself changes: a person loses the ability to" feel " in his life, which floats before his eyes, like a video clip. It is difficult to underestimate the possible social consequences of such insensitivity, which is manifested, among other things, in ignoring the educational impact of the family, teachers, culture and art. Such a situation is determined by the specific essential qualities of virtuality, which are interpreted as follows by V. L. Silaeva: virtual reality phenomena always differ in some partial or non-incarnate existence, they are always characterized by a certain lack, the absence of essential features inherent in the phenomena of everyday empirical reality. They represent an incomplete, reduced presence that is not capable of a stable and self-sustaining presence in the world. Algorithms and stereotypes of actions that are familiar in the virtual world, being brought into reality, everyday life, often become the starting point of deviant behavior. It should be noted that currently education virtualization is a complex structured combination of full-time and part-time education and self-education, which is associated primarily with the active development of telecommunications systems, multimedia, information broadcasting, and extensive network communication capabilities. The penetration of virtuality into the space of education is completely natural and is caused by economic and socio-cultural factors. However, it is important to pay attention to the fact that virtuality should not absorb, replace the existing educational system, remaining in it only one of the components that ensure that the learning results meet the requirements of the time. It should retain the status of a tool that optimizes educational activities. Virtualization of the educational process, however, should be carried out in parallel with increasing the information culture of the individual, developing the ability to find, analyze, systematize information, separate true knowledge from false, and use information for self-creation. The use and involvement of modern means of communication in the field of education is determined by its very specificity. As noted by A. Staradchenko, "systemically differentiated from the external environment parts-the structure of the educational process-constantly communicate cyclically, are in the process of constant correlation, self-coordination of subsystems in elementary and more complex communicative operations, i.e., refer to themselves. Therefore, education is a self-referential communication system. Communication of interaction in education is determined by a specific need, i.e. it is subject to a specific goal - the process of knowledge transfer. In addition, education is also the self-reproduction of communications". Communication is one of the main elements of the educational process, which requires constant improvement of the quality of communication and expansion of its means. In this regard, telecommunications technologies that allow remote learning are important. Modern distance learning in online mode is characterized by flexibility (regardless of time and place), strengthening the capabilities of teachers and students by attracting new multimedia technologies that are unattainable in traditional education. Distance learning involves the following activities: teleconferences of various types, mailing of electronic educational materials, correspondence between the teacher and the student, communication and consultation online. According to I. G. Borisenko, for the sequencing process of the educational space characterized by the following phenomenon: "the transformation of information technology in the current form of the sequencing process; the growing influence of modern information technologies in the educational process; the pluralization of practices the formation and functioning of subjects of educational process". In these conditions, the significant goal of education is not in itself the preparation of the individual for his future professional activity by accumulating a certain amount of knowledge, already systematized and verified, in a limited time period of training, but the comprehensive development of the individual, mastering the ways of working with information, acquiring and generating knowledge. These skills make it possible not only to carry out continuous education and self-development throughout life, but also to successfully navigate and function as a professional in the 
modern information world. Thus, modernity comes to the formation of a new educational paradigm, one of the foundations of which is the understanding of education as a continuous process that covers the entire life path of the individual.: "If the essence of the old education system can be expressed by the formula "education for life", then the new educational system can be presented as a slogan: "education for life", and this is nothing more than a kind of strategy of education for the future".

In addition to distant education, another effective way to organize a virtual educational space is to create educational portals. Currently, this is an actively developing and quite popular area of activity. Accordingly, the volume of literature that reveals the experience of the formation and functioning of educational portals is constantly growing. In world educational practice, there are three types of educational portals: organizational-oriented portals that help applicants choose a full-time educational institution. In Russia, the most developed educational portals provide the ability to search for and access all the necessary information on the subjects of interest to the student. This feature is implemented primarily in the form of an electronic library.

\section{CONCLUSION}

Thus, we can state the fact that Informatization and computerization of education, the widespread use of the global Internet lead to radical changes in the educational system as a whole. The tremendous power of influence and the rate of penetration into all educational structures determine the present need for a reasonable use of technical means, which involves the comprehensive development of the individual and leveling the factors leading to its self-destruction.

The current economic and socio-cultural situation is such that the education system currently has no choice whether or not to use any technologies. The actions of the educational system in this direction are quite strictly regulated by modern market relations: all new directions of professional training are required, knowledge is rapidly devalued, supplemented, modified, and the need to include future specialists in a strictly defined circle of important competencies for modern society is supported.

\section{REFERENCE LIST}

Bokachev I. A., lukinova I. A. Virtualization of the modern education system: for and against / / Humanities, socio-economic and social Sciences. No. 1. 2015. Pp. 15-19. (in Russian).

Baudrillard Zh. Symbolic exchange and death. Moscow: Dobrosvet, 2000. P. 113. (in Russian).

Borisenko I. G. Virtualization of the national educational space: socio-philosophical analysis: author's thesis ... candidate of Philos. Sciences (social philosophy). Krasnoyarsk, 2016. (in Russian).

Chernykh S. I. Change in the educational space in the information age: socio-philosophical analysis: author. dis. ... doctor of Philos. Sciences: 09.00.11 [Electronic resource] / Chernykh Sergey Ivanovich. Novosibirsk, 2012. 28 p. - URL: http://www.dslib.net/soc-filosofia/ izmenenie-obrazovatelnogoprostranstva-v-informacionnuju-jepohu-socialno.html. (in Russian).

Ivanov D. V. Virtualization of society. Saint Petersburg, 2000. (in Russian).

Khrapov S. A., Novikov A. S. Virtual sociality: sociocultural analysis // Historical, philosophical, political and legal Sciences, cultural studies and art criticism. Questions of theory and practice. 2013. No. 7 (33). $\mathrm{CH}$. 2. P. 189-193. (in Russian).

Khutorskoy A.V. Virtual education and Russian cosmism // Online magazine "Eidos". 1999. January 20. URL: http://www.eidos.ru/ jomal/1999/0120.htm (reference date: 12.09.2016). (in Russian).

Kirillova N. media Culture: from modern to postmodern. Moscow, 2005. (in Russian).

Maslikhova L. I., Petrenko V. R., Korshunova S. A. Achievements of technical education of the voronezh region as a guarantee of successful development of the country and the region (rev. On the book: 110 years of technical education of the voronezh region : anniversary edition. - Voronezh: VSTU publishing house, 2018. - 240 p). Bulletin of the Voronezh state University. Series: Problems of higher education. 2019. no. 4. Pp. 114-117. (in Russian).

Maslikhova L.I., Radugina O.A., Pogorelsky A.V. Discussions about causes of dissolution of the USSR in modern American Political Science. 7th International conference on Education and Social Sciences 
Abstracts \& Proceedings. 2020. C. 113-117. (in Russian).

Masuda, Y. The information society. / Y. Masuda. - Bethesda, 1980. (in Russian).

Masuda, Y. The Information Society as Post-Industrial Society / Y. Masuda. - Washington, dc:World Future Society, 1981. (in Russian).

Nosov N. A. Virtual psychology // Proceedings of the virtualistics laboratory. Vol. 6. Moscow: agraf, 2000. 432 p. (in Russian).

Ovechkin V. p. Education in a changing cultural and technological environment // Pedagogy. 2005. no. 10. Pp. 18-28. (in Russian).

Rudnev V. Away from reality. Moscow, 2000. (in Russian).

Silaeva V. L. Substitution of reality as a socio-cultural mechanism of virtualization of society: dis. ... Cand. Philos. nauk. M., 2004. (in Russian).

Stradanchenko A. A. Virtualization of education // Humanities and social Sciences. 2014. no. 2. Pp. 429-432. (in Russian).

Tapscott, D. Electronic and digital society: Pros and cons of the age of network intelligence. Dubinsky And. Ed. Pisareva, S.-M.: Relf Buk, 1999. 432 p. (in Russian).

Virtualization of education. Media analysis. URL: http://www.mediagnosis. ru/mshsen/4-1.htm (reference date: 20.01.2016). (in Russian).

Yukhvid A.V. Computer virtual technologies as a new techno-social phenomenon: socio-philosophical analysis: autoref. dis. ... doctor of Philos. Sciences: 09.00.11 [Electronic resource] / Yukhvid Alexey V. M., 2013. 49 p. URL: http://www.dslib.net /ontologia/jevristicheskie-vozmozhnostikompjuternyh-virtualnyh-tehnologij.html. (in Russian). 